\title{
Álvarez de Miranda, P. (2018): El género y la lengua. Madrid: Turner,
}

$91 \mathrm{pp}$.

EL LIBRO que aquí se presenta es fruto de la reelaboración y ampliación de varios artículos publicados por Pedro Álvarez de Miranda en el diario El País, en la revista electrónica Rinconete — editada por el Centro Virtual Cervantes - y en distintas publicaciones científicas. El propósito de este ensayo es ofrecer una explicación pormenorizada sobre cómo opera el género gramatical en la lengua española. Asimismo, muestra una visión crítica acerca de las distintas «soluciones» con que se pretende evitar el uso del masculino como género inclusivo, todo ello alumbrado y refutado a partir de infinitud de ejemplos y casos de reciente actualidad. Ello ilustra el firme objetivo de servir como obra de referencia tanto para un público general como especializado en lo que concierne al denominado «sexismo lingüístico». Hay en este libro, por tanto, un deseo por acercar una reflexión no solamente acerca del género, sino también sobre cómo funciona una lengua y cómo actuamos - y los límites de tal actuación-con relación a ella.

En la primera parte del libro se introduce qué es el género gramatical y por qué el masculino es el género no marcado o «por defecto» en el español. Para ello, se remonta al origen de la distinción de género, para la que, según el autor, «es más que posible que la condición de género no marcado que tiene el masculino sea trasunto de la prevalencia ancestral de patrones androcéntricos» (pág. 20). Partiendo de esta idea, Álvarez de Miranda explicita una de las ideas que vertebran esta obra: que, para que cambie la lengua, es necesario que primero cambie la sociedad, y no a la inversa. Esto se debe a que, si bien cualquier lengua es producto de los hablantes, los cambios en su gramática no son el resultado de la intervención o planificación consciente de un hablante o grupo de hablantes, sino de un lento proceso que ocurre «de abajo arriba y tras un refrendo mayoritario de los hablantes». Por tal razón, las propuestas de ciertas guías de lenguaje no sexista sobre el uso de la @, la $e$ o la $x$ 
-i.e., el uso de la $x$ en sustitución de la vocal de la flexión de género para evitar el uso del género no marcado- difícilmente pueden tener amplia aceptación entre los hispanohablantes, puesto que suponen una intervención en la morfología y la sintaxis del español, el armazón de una lengua que no ha mutado «desde tiempos medievales, y no es en absoluto previsible que lo haga» (pág. 87). Tal y como explica el autor, las innovaciones o creaciones no tienen igual cabida en todos los planos del sistema lingüístico, sino que se dan, sobre todo, en el ámbito del léxico, siempre y cuando tengan suficiente aceptación entre la comunidad de hablantes.

Es importante, asimismo, destacar la asociación que hace entre el género no marcado y el número no marcado; esto es, equiparando el género masculino al número singular en determinados casos en los que este último engloba también al plural, como en El perro es el mejor amigo del hombre, entendido como los perros son los mejores amigos de los hombres (pág. 14). Lo que diferencia ambos rasgos es que, mientras la oposición entre singular y plural es un contraste entre uno o más de uno, la flexión de género alberga subsistemas de índole semántica y morfológica que no son uniformes y que, como explica el autor a lo largo de la obra, dependen de cada caso particular. Son las cuestiones semánticas referentes a las categorías léxicas - y más concretamente, las que afectan a la relación entre el género gramatical y el sexo/género de los referentes- las que suscitan mayor debate entre las propuestas que cuestionan el funcionamiento de la moción de género en español.

Además, en este primer apartado, Álvarez de Miranda ofrece un análisis crítico de la propuesta de ciertas guías de estilo por emplear sustantivos colectivos (el profesorado, la ciudadanía) en lugar de sustantivos que denotan persona (los profesores, los ciudadanos). Si bien considera que esta opción es un «hábil e interesante recurso» para evitar el circunloquio del desdoblamiento (pág. 28), el autor expone dos objeciones a tal idea: por un lado, la existencia de «casillas vacías» en el caudal léxico del español como ocurre, verbigracia, con los respectivos sustantivos colectivos de chicos, conductores, trabajadores, escritores, empleados, etc. Por otro lado, recurre al recurso de la variatio - esto es, el empleo de voces sinónimas para evitar la repetición de uno o varios términos- para no sustituir de forma sistemática el masculino genérico (los estudiantes) por el correspondiente colectivo si lo hubiera (el estudiantado).

En la segunda parte de esta obra se expone un análisis pormenorizado del género gramatical de los nombres de persona. Para tal fin, muestra una categorización en tres grupos, a saber: un primer grupo en el que se encuentran los sustantivos que flexionan como, v.gr., el niño / la niña o el perro / la perra. En el segundo grupo incluye a los denominados comunes en cuanto al género; estos sustantivos 
no flexionan, pero sí presentan rasgos de género a través del determinante, como en el deportista / la deportista o el modelo / la modelo. En el tercer grupo incluye a los epicenos, que son aquellos que, mediante un único género, pueden referirse a individuos de ambos sexos, como ocurre en la persona, la víctima o el vástago. A partir de esta clasificación, se analizan casos de recientes innovaciones con relación a estos paradigmas, como en el caso de portavoza. Acerca de esta creación, a juicio del autor, «no es “más femenino” portavoza que la portavoz» (pág. 46), puesto que la moción de género femenino ya se expresa en el artículo por ser un sustantivo común en cuanto al género.

Es preciso mencionar, asimismo, algunas consideraciones que aporta el autor sobre algunos sustantivos con referente femenino. Por un lado, responsabiliza a la Real Academia Española de no haber ofrecido recomendaciones de uso en formas que muestran vacilación en cuanto al género, como la jueza / la juez o la médica / la médico. Por otro lado, propone que, en aquellos sustantivos que designen profesión, se normalicen las formas flexionadas en femenino, como en abogada, médica, directora o ingeniera y se superen, por tanto, las formas comunes en cuanto al género correspondientes con el fin de normalizar la presencia de mujeres en dichos cargos. Esto ejemplifica que el cambio lingüístico siempre va uno o dos pasos por detrás del cambio social, y no a la inversa.

En el último apartado se abordan los distintos tratamientos que han tenido las propuestas del «lenguaje inclusivo» por parte de la Académie Française y la Accademia della Crusca. De ello se deduce, a juzgar por la postura adoptada de la Real Academia Española, que esta pretende estar más cerca de la sociedad que sus homólogas. Según Álvarez de Miranda, de las directrices de la Academia francesa en relación con el sexismo en el lenguaje se deduce que es, en palabras del autor, «más masculinista» que la Academia española (pág. 78). O, en otras palabras, que está más alejada del cambio social que la RAE. Esto lo ejemplifica a la perfección mencionando un caso de actualidad, como es la colaboración de la Academia española con el Gobierno para que el texto de la Constitución visibilice a las mujeres en la medida de lo posible.

En suma, este ensayo es la prueba fehaciente de la intención de Pedro Álvarez de Miranda por aportar un análisis riguroso y con base en el estudio gramatical acerca del lenguaje inclusivo. Todo ello aparece debidamente conjugado con multitud de ejemplos actuales, cuyos análisis y refutaciones se agradecen sobremanera para, tras su lectura, poder tener una mirada crítica hacia ciertos discursos que se leen y se escuchan a diario. Además de las sobradas razones - algunas de las cuales, espero, se han recogido en estas líneas - para considerar el género como una convención gramatical 
arbitraria y de difícil sustitución, aporta una reflexión que conviene recordar: las lenguas cambian cuando lo hace la sociedad, de modo que cualquier intervención en la lengua, por muy loable que sea la intención que la motive, debe ir precedida de un cambio en lo social para que arraigue. Por eso, una alcaldesa ya no es la esposa de un alcalde, sino la mujer que ocupa la alcaldía.

- RubÉn CONDE RuBio 